\title{
PENGGUNAAN MEDIA PEMBELAJARAN ZOOMING PRESENTATION UNTUK MENINGKATKAN HASIL BELAJAR SISWA KELAS X PADA KONSEP SUHU DAN KALOR
}

\author{
Putri Zakiyatul Zannah ${ }^{1}$, Diah Mulhayatiah ${ }^{2}$, Fathiah Alatas ${ }^{3}$ \\ Pendidikan Fisika FITK UIN Syarif Hidayatullah Jakarta, \\ 1diahmfis@gmail.com, ${ }^{2}$ fathiahalatas@gmail.com, ${ }^{3}$ putrizakiyatul@gmail.com
}

\begin{abstract}
This study aims to determine the using of zooming learning media presentation on the results of class $\mathrm{X}$ student to the concept of temperature and heat. Learning media zooming presentation was made using Prezi application. This research was conducted at SMAN 12 South Tangerang. The study took place in March-April 2014. The research method used was a quasi-experimental design with nonequivalent control group design and purposive sampling techniques. Samples taken are the number of students of class $X$ 33. instrument used was a test instrument in the form of multiple choice questions and non - test in the form of a questionnaire. Data results instrument test were analyzed quantitatively, while the non test result data were analyzed qualitatively. Based on data analysis, the result of class X student to the concept of temperature and heat . The results of hypothesis testing against the data posttest shows the value $\mathrm{t}=4.53$ and $\mathrm{t}$ table value $=1.998 . \mathrm{T}_{\text {count }}>\mathrm{T}_{\text {table }}$, so $\mathrm{H}_{0}$ is rejected and $\mathrm{H}_{\mathrm{a}}$ accepted. The average results of student learning using learning media presentation zooming higher than the average of student learning outcomes without the use of instructional media zooming presentation. Student learning outcomes experimental class is superior in improving the ability to remember $(\mathrm{C} 1)$, understanding $(\mathrm{C} 2)$, apply (C3), and analyze (C4). Furthermore, based on data analysis based on questionnaire responses nontes students to study media presentation are zooming in both categories with a percentage of $76 \%$.
\end{abstract}

Keywords: desktop Prezi, the zooming presentation, physics learning outcomes, instructional media

\begin{abstract}
Abstrak
Penelitian ini bertujuan untuk mengetahui penggunaan media pembelajaran zooming presentation terhadap hasil belajar siswa kelas X pada konsep suhu dan kalor. Media pembelajaran zooming presentation ini dibuat menggunakan aplikasi Prezi. Penelitian ini dilakukan di SMA Negeri 12 Tangerang Selatan. Penelitian berlangsung pada bulan Maret-April 2014. Metode penelitian yang digunakan adalah kuasi eksperimen dengan desain nonequivalent control group design dan teknik pengambilan sampel purposive sampling. Sampel yang diambil adalah kelas X dengan jumlah siswa 33. Instrumen yang digunakan adalah instrumen tes berupa soal pilihan ganda dan non-tes berupa angket. Data hasil instrument tes dianalisis secara kuantitatif, sedangkan data hasil non-tes dianalisis secara kualitatif. Berdasarkan analisis data, diperoleh hasil belajar siswa kelas X pada konsep suhu dan kalor. Hasil uji hipotesis terhadap data posttest menunjukkan nilai $\mathrm{t}_{\text {hitung }}=4,53$ dan nilai $\mathrm{t}_{\text {tabel }}=1,998$. Nilai $\mathrm{t}_{\text {hitung }}$ $>t_{\text {tabel}}$, sehingga $\mathrm{H}_{0}$ ditolak dan $\mathrm{H}_{\mathrm{a}}$ diterima. Rata-rata hasil belajar siswa yang menggunakan media pembelajaran zooming presentation lebih tinggi dibandingkan rata-rata hasil belajar siswa tanpa menggunakan media pembelajaran zooming presentation. Hasil belajar siswa kelas eksperimen lebih unggul dalam meningkatkan kemampuan mengingat (C1), memahami (C2), menerapkan (C3), dan menganalisis (C4). Selanjutnya berdasarkan analisis data nontes berdasarkan angket respon siswa terhadap media pembelajaran zooming presentation berada pada kategori baik dengan persentase $76 \%$.
\end{abstract}

Kata kunci: Prezi desktop, zooming presentation, hasil belajar fisika, media pembelajaran

\section{PENDAHULUAN}

Pembelajaran menurut UNESCO pada tahun 1997 mengungkapkan bahwa pembelajaran didasari oleh empat pilar utama (The Four Pillars of Education). Empat pilar utama tersebut diantaranya, belajar untuk mengetahui (Learning to know), belajar untuk berkarya (Learning to do), belajar untuk berkembang utuh (Learning to be) dan belajar untuk hidup bersama (Learning to live together). Hal tersebut merupakan aspek filosofis yang harus diterapkan dalam menjalankan proses pembelajaran.

Penbelajaran merupakan suatu kegiatan yang melibatkan seorang pembelajar untuk memperoleh pengetahuan, keterampilan dan nilai-nilai positif dengan memanfaatkan berbagai sumber untuk belajar. Pembelajaran melibatkan dua pihak yaitu siswa sebagai pembelajar dan guru sebagai fasilitator. Belajar membutuhkan interaksi, hal ini 
menunjukkan bahwa proses pembelajaran merupakan proses komunikasi artinya proses belajar mengajar terjadi proses penyampaian pesan dari sumber pesan kepada penerima pesan (Sadiman dkk, 1986). Baik buruknya sebuah komunikasi ditunjang oleh penggunaan media dalam komunikasi tersebut.

Berdasarkan hasil observasi di Tangerang Selatan pada SMA yang masih menggunakan kurikulum KTSP 2006. Diperoleh informasi bahwa pada tahun ajaran 2011-2012 Kriteria Ketuntasan Minimum (KKM) untuk mata pelajaran fisika kelas $\mathrm{X}$ sebesar 75. Akan tetapi, siswa memperoleh nilai rata-rata kurang dari 75 . Rendahnya hasil belajar tersebut disebabkan oleh beberapa faktor diantaranya adalah pembelajaran yang dilakukan masih bersifat konvensional dan jarang sekali menggunakan media pembelajaran. Selain itu, diperoleh informasi bahwa media pembelajaran yang digunakan masih monoton dan kurang inovatif. Akibatnya minat belajar siswa menjadi rendah. Agar siswa memiliki minat belajar yang tinggi maka proses pembelajaran yang dilaksanakan guru harus berjalan dengan baik dan efektif. Hal ini dapat diterapkan dalam pembelajaran fisika, karena konsep fisika bersifat makroskopik yakni konsep suhu dan kalor.

Berdasarkan uraian tersebut penyampaian materi ajar berlangsung lebih efektif jika dalam pembelajaran tersebut menggunakan media pembelajaran. Pemilihan media pembelajaran yang tepat harus memperhatikan dan menyesuaikan kebutuhan materi pelajaran agar fungsi media sebagai alat yang dapat meningkatkan pemahaman dan minat belajar. Salah satunya adalah dengan menggunakan media pembelajaran zooming presentation, dimana hal ini sejalan dengan penelitian Artem dengan menggunakan zooming presentation dapat menyajikan penjelasan yang interaktif dalam pembelajaran (Pecheny, 2010).

Kata medium dalam American Heritage Electronic Dictionary (1991) diartikan sebagai alat untuk mendistribusikan dan mempresentasikan informasi. Media berasal dari bahasa latin dan merupakan bentuk jamak dari kata "medium" yang secara harfiah berarti "perantara" yaitu perantara sumber pesan dengan penerima pesan (Munir, 2012).

Media pembelajaran zooming presentation merupakan salah satu aplikasi terbaru yang memiliki tampilan fresh, unik, menarik dan memiliki kecanggihan dalam memperbesar dan memperkecil tampilan serta dapat memadukan antara video, gambar maupun animasi. Dibuat menggunakan aplikasi Prezi.

Prezi awalnya dikembangkan oleh arsitek Hungaria bernama adam Somlai Fischer sebagai alat visualisasi arsitektur. Prezi sebagai alat untuk mengembangkan berbagai ide dalam bentuk visual dan format menarik yang bersifat naratif. Presentasi melalui Prezi dibuat pada sebuah kanvas yang tidak terbatas oleh bingkai. Hal ini memudahkan penyampaian dalam penggabungan teks, gambar dan multimedia lainnya. Materi-materi yang disampaikan di atas kanvas dapat ditarik, digeser, dapat berputar ke kiri dan ke kanan agar kelihatan lebih menarik tanpa perlu mengganti slide.Satu tampilan presentasi dapat dibuat dengan elemen yang berbeda pada sajiannya untuk membuat animasi (Rosadi, 2013). Prezi juga memiliki keistimewaan pada zooming in dan out, yang dapat memperlihatkan sajian secara detail dimana memberikan kesan yang mendalam pada penerima pesan (Diamond, 2010).

Prezi adalah sebuah perangkat lunak untuk presentasi berbasis internet.Selain untuk presentasi, prezi juga dapat digunakan sebagai alat untuk mengeksplorasi dan berbagi ide di atas kanvas virtual.Prezi menjadi unggul karena program ini menggunakan Zooming User Interface (ZUI), yang memungkinkan pengguna prezi untuk memperbesar dan memperkecil tampilan media presentasi (Diamond, 2010).

Tahapan membuat Media Pembelajaran Zooming Presentation menggunakan aplikasi prezi adalah langkah pertama adalah masuk ke halaman web www.prezi.com, kemudian mendaftar masuk. Setelah mendaftar lalu mulai mengunduh prezi desktop dan mengaktifkannya. Kemudian prezi dapat digunakan secara offline. Langkah selanjutnya, mulai membuat presentasi menggunakan prezi, menuliskan teks pada kanvas. Lalu memperbesar dan memperkecil teks serta mengatur posisi teks. Memasukkan video, gambar, dan animasi serta mengatur path untuk tampilan otomatis, dan prezi siap menampilkan presentasi (Embi, 2011).

Hasil belajar adalah kemampuankemampuan yang dimiliki siswa setelah menerima pengalaman belajarnya. Hasil belajar dapat dipahami dengan menjelaskan dua kata yaitu hasil dan belajar. Pengertian hasil (product) menunjukan pada suatu perolehan akibat dilakukannya suatu aktivitas atau proses yang mengakibatkan berubahnya input secara fungsional. Sehingga, setelah mengalami belajar, siswa berubah perilakunya (Sudjana, 2011). 
Gagne membagi lima kategori hasil belajar, yakni (a) informasi verbal; (b) keterampilan intelektual; (c) strategi kognitif; (d) sikap; dan (e) keterampilan motoris (Sudjana, 2011). Hasil belajar adalah perubahan perilaku, bertambah pengetahuan, dan kemampuan keterampilan yang dimiliki siswa setelah mengikuti proses belajar mengajar yang diberikan guru sehingga siswa menjadi lebih baik lagi dari sebelumnya. Dalam sistem pendidikan nasional, rumusan tujuan pendidikan, baik tujuan kurikuler maupun tujuan instruksional, menggunakan klasifikasi hasil belajar dari Benyamin Bloom yang secara garis besar terbagi menjadi tiga ranah, yakni ranah kognitif, ranah afektif, dan ranah psikomotorik. Ranah kognitif berkenaan dengan hasil belajar intelektual yang terdiri dari enam aspek, yaitu: 1) Mengingat (C1); 2) Memahami (C2); 3)Mengaplikasikan atau Menerapkan (C3); 4) Menganalisis (C4); 5) Mengevaluasi (C5) ; 6) Menghasilkan karya atau mencipta (C6) (Anderson-Krathwoll, 2010).

Penelitian ini dilakukan dengan tujuan yang ingin dicapai yaitu penggunaan media pembelajaran zooming presentation untuk meningkatkan hasil belajar siswa kelas X pada konsep suhu dan kalor.

\section{METODE PENELITIAN}

Penelitian ini dilaksanakan semester genap Tahun Ajaran 2013-2014 pada bulan Maret s.d April di SMA Negeri 12 Tangerang Selatan. Metode yang digunakan dalam penelitian ini adalah metode eksperimen semu (quasi experiment). Desain eksperimen semu yang digunakan adalah nonequivalent control group design dimana kelompok eksperimen dan kelopok kontrol tidak dipilih secara random (Sugiono, 2013). Populasi dalam penelitian ini dibedakan antara populasi secara umum dengan populasi target atau target population. Populasi umum dalam penelitian ini adalahseluruh siswa SMA Negeri 12 Tangerang Selatan dan populasi target adalah siswa kelas X di SMA Negeri 12 Tangerang Selatan yang terdiri dari kelas X.1 sampai dengan X.7.

Pengambilan sampel dilakukan dengan menggunakan purposive sampling merupakan teknik penentuan sampel dengan pertimbangan khusus sehingga layak dijadikan sampel (Sugiono, 2013). Sampel yang digunakan dalam penelitian ini adalah siswa kelas X.1 sebagai kelas eksperimen yang mendapatkan pembelajaran dengan media pembelajaran zooming presentation. Sedangkan kelas kontrolnya adalah siswa kelas X.3 yang mendapat pembelajaran konvensional dengan media papantulis yang biasa dilakukan oleh guru fisika setempat.

Pada penelitian ini teknik pengumpulan data yang digunakan adalah teknik tes dan nontes. Jenis teknik tes digunakan sebagai tes hasil belajar diperoleh dari hasil pretest dan posttest siswa. Adapun jenis nontes yang digunakan adalah angket persepsi siswa mengenai penggunaan media pembelajaran zooming presentation. Instrumen tes pada penelitian ini berupa tes objektif pilihan ganda dengan lima pilihan sebanyak 25 Soal. Instrumen nontes yang digunakan berupa angket.

Pada penelitian ini, angket digunakan untuk mengetahui respon siswa mengenai penggunaan media pembelajaran zooming presentation dalam proses pembelajaran fisika konsep suhu dan kalor. Angket yang digunakan dalam penelitian ini adalah model angket skala Likert yang berbentuk ratingscale.

\section{HASIL DAN PEMBAHASAN}

Berdasarkan hasil perhitungan pretest dan posttest kelas eksperimen dan kelas kontrol yang terdiri dari 33 siswa, diperoleh rekapitulasi data dapat dilihat pada Tabel 1.

Tabel 1. Rekapitulasi Pretest dan Posttest Kelas Eksperimen dan Kelas Kontrol

\begin{tabular}{lcccc}
\hline \multirow{2}{*}{ Data } & \multicolumn{2}{c}{ Pretest } & \multicolumn{2}{c}{ Posttest } \\
\cline { 2 - 5 } & E & K & E & K \\
\hline Nilai & 16 & 16 & 60 & 52 \\
Terendah & & & & \\
Nilai & 44 & 44 & 96 & 92 \\
Tertinggi & & & & 68 \\
Rata-rata & 26,18 & 30,72 & 77,57 & 68 \\
Median & 26,44 & 30,68 & 76,35 & 66,76 \\
Modus & 28,83 & 29,78 & 74,5 & 68,5 \\
Standar & 6,22 & 5,16 & 7,90 & 9,16 \\
Deviasi & &
\end{tabular}

Berdasarkan Tabel 1 terlihat bahwa, nilai rata-rata (mean) kelas eksperimen pada saat pretest adalah sebesar 26,18 sementara pada kelas kontrol yaitu 30,72. Pada saat posttest nilai rata-rata (mean) kelas eksperimen mencapai 77,57 sedangkan kelas kontrol sebesar 68. Berikut diagram nilai rata-rata (mean) kelas eksperimen dan kelas kontrol pada saat pretest dan Posttest dapat dilihat pada Gambar 1. 


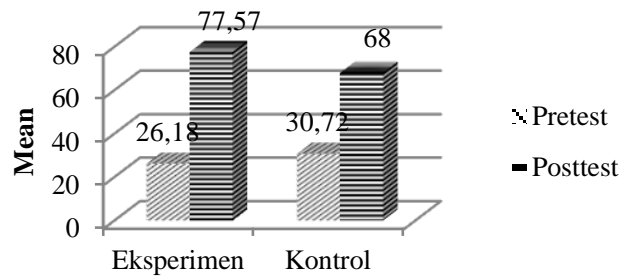

Gambar 1. Diagram Nilai Rata-rata Kelas Kontrol dan Eksperimen

Gambar 1 menunjukkan pretest kelas eksperimen memiliki nilai rata-rata (mean) yang lebih rendah dibandingkan kelas kontrol dan pada saat posttest kelas eksperimen memiliki nilai ratarata (mean) yang lebih tinggi dibandingkan kelas kontrol. Namun, baik kelas eksperimen maupun kelas kontrol mengalami peningkatan nilai rata-rata (mean) hasil belajar siswa setelah diberikan perlakuan yang berbeda. Nilai rata-rata (mean) kelas eksperimen meningkat sebesar 49,82.

Hasil pretest dan posttest pada konsep suhu dan kalor diketahui persentase berdasarkan jenjang kognitif. Persentase setiap jenjang kognitif dapat dilihat pada Tabel 2 di bawah ini:

Tabel 2. Hasil Pretest dan Posttest Berdasarkan Jenjang Kognitif

\begin{tabular}{lcccc}
\hline Jenjang Kognitif & \multicolumn{2}{c}{ Pretest } & \multicolumn{2}{c}{ Posttest } \\
\cline { 2 - 5 } & $\mathbf{E}$ & $\mathbf{K}$ & $\mathbf{E}$ & $\mathbf{K}$ \\
\hline Mengingat $\left(\mathrm{C}_{1}\right)$ & $27 \%$ & $51 \%$ & $69 \%$ & $65 \%$ \\
Memahami $\left(\mathrm{C}_{2}\right)$ & $38 \%$ & $27 \%$ & $82 \%$ & $79 \%$ \\
Menerapkan $\left(\mathrm{C}_{3}\right)$ & $26 \%$ & $29 \%$ & $76 \%$ & $64 \%$ \\
& & & & \\
Menganalisis $\left(\mathrm{C}_{4}\right)$ & $19 \%$ & $25 \%$ & $72 \%$ & $67 \%$
\end{tabular}

Tabel 2 menunjukkan presentase pretest dan posttest kelas eksperimen dan kelas kontrol berdasarkan jenjang kognitif. Pada saat pretest kemampuan kelas eksperimen dalam mengingat $\left(\mathrm{C}_{1}\right)$ 27\%, memahami $\left(\mathrm{C}_{2}\right) 38 \%$, menerapkan $\left(\mathrm{C}_{3}\right)$ $26 \%$, menganalisis $\left(\mathrm{C}_{4}\right) 19 \%$, sedangkan pada kelas kontrol kemampuan mengingat $\left(\mathrm{C}_{1}\right) 51 \%$, memahami $\left(\mathrm{C}_{2}\right) 27 \%$, menerapkan $\left(\mathrm{C}_{3}\right) 29 \%$, dan menganalisis $\left(\mathrm{C}_{4}\right)$ 25\%. Pada saat posttest kemampuan kelas eksperimen dalam mengingat $\left(\mathrm{C}_{1}\right)$ adalah 69\%, memahami $\left(\mathrm{C}_{2}\right)$ 82\%, menerapkan $\left(\mathrm{C}_{3}\right) 76 \%$, dan menganalisis $\left(\mathrm{C}_{4}\right) 72 \%$. Sedangkan pada kelas kontrol, berdasarkan jenjang kognitif dalam mengingat $\left(\mathrm{C}_{1}\right)$ sebesar $65 \%$, memahami $\left(\mathrm{C}_{2}\right) 79 \%$, menerapkan $\left(\mathrm{C}_{3}\right) 64 \%$, dan menganalisis $\left(\mathrm{C}_{4}\right)$ 67\%. Data tersebut terlihat peningkatan jenjang kognitif antara pretest dan posttest.
Tabel 3. Hasil Perhitungan Uji Normalitas Kai Kuadrat Pretest dan Posttest Kelas Eksperimen dan Kelas Kontrol

\begin{tabular}{lcccc}
\hline \multirow{2}{*}{ Statistik } & \multicolumn{2}{c}{ Pretest } & \multicolumn{2}{c}{ Posttest } \\
\cline { 2 - 5 } & $\mathbf{E}$ & $\mathbf{K}$ & $\mathbf{E}$ & $\mathbf{K}$ \\
\hline $\mathrm{X}^{2}{ }_{\text {hitung }}$ & 3,74 & 5,72 & 4,55 & 4,97 \\
$\mathrm{X}_{\text {tabel }}$ & \multicolumn{2}{c}{9,48} & 11,07 & 12,59 \\
Keputusan & \multicolumn{3}{c}{ Data terdistribusi normal } \\
\hline
\end{tabular}

Uji normalitas nilai posttest antara kelas eksperimen dan kelas kontrol berbeda, Keputusan diambil berdasarkan pada ketentuan pengujian hipotesis normalitas yaitu $\mathrm{X}_{\text {hitung }}^{2}<\mathrm{X}_{\text {tabel }}^{2}$ maka dapat dinyatakan data terdistribusi normal.

Pengujian homogenitas juga dilakukan pada kedua data pretest dan posttest untuk menunjukkan bahwa data berasal dari populasi yang tidak jauh berbeda keragamannya. Hasil yang diperoleh dari uji homogenitas dapat dilihat pada Tabel 4 di bawah ini:

Tabel 4. Hasil Perhitungan Uji Homogenitas

\begin{tabular}{lcccc}
\hline \multirow{2}{*}{ Statistik } & \multicolumn{2}{c}{ Pretest } & \multicolumn{2}{c}{ Posttest } \\
\cline { 2 - 5 } Nilai Varians & $\mathbf{E}$ & $\mathbf{K}$ & $\mathbf{E}$ & $\mathbf{K}$ \\
& 38,77 & 26,70 & 62,45 & 84,07 \\
Nilai F & & & \\
hitung & \multicolumn{2}{c}{1,45} & \\
Nilai F & & & \\
Kabel & \multicolumn{3}{c}{1,84} \\
Keputusan & \multicolumn{3}{c}{ Kedua data homogen } \\
\hline
\end{tabular}

Nilai $F_{\text {tabel }}$ diambil dari tabel $F$ statisik pada taraf signifikansi 5\%. Keputusan diambil berdasarkan pada ketentuan pengujian hipotesis homogenitas yaitu jika $\mathrm{F}_{\text {hitung }}<\mathrm{F}_{\text {tabel }}$, maka dinyatakan kedua data homogen.

Pengujian hipotesis penelitian data pretest dan posttest dapat dilihat pada Tabel 5 di bawah ini:

Tabel 5. Hasil Perhitungan Uji Hipotesis

\begin{tabular}{lcc}
\hline \multicolumn{1}{r}{ Statistik } & Pretest & Posttest \\
\hline $\mathrm{t}_{\text {hitung }}$ & 1,89 & 4,53 \\
$\mathrm{t}_{\text {tabel }}$ & \multicolumn{2}{c}{1,998} \\
Keputusan & $\mathrm{H}_{\mathrm{a}}$ ditolak & $\mathrm{H}_{\mathrm{a}}$ diterima \\
\hline
\end{tabular}

Nilai $\mathrm{t}_{\text {tabel }}$ diambil dari Tabel $\mathrm{T}$ statistik pada taraf signifikansi 5\%. Keputusan diambil berdasarkan pada ketentuan pengujian hipotesis, yaitu jika $t_{\text {hitung }}>t_{\text {tabel }}$, maka dinyatakan bahwa penelitian ini dapat menguji kebenaran hipotesis yaitu terdapat pengaruh media pembelajaran zooming presentation terhadap hasil belajar siswa kelas X pada konsep suhu dan kalor. Hal tersebut ditunjukkan dari rata-rata hasil belajar siswa kelas eksperimen lebih tinggi daripada rata-rata hasil belajar siswa kelas kontrol. Sedangkan hasil data 
angket yang telah diperoleh selanjutnya diolah secara kualitatif. Hasil perhitungan dapat dilihat pada Tabel 6

Tabel 6. Hasil Angket Penggunaan Media Pembelajaran Zooming Presentation

\begin{tabular}{|c|c|c|c|}
\hline \multirow{2}{*}{ No. } & \multirow{2}{*}{ Indikator Angket } & \multicolumn{2}{|c|}{ Kelas Eksperimen } \\
\hline & & $\%$ & Ket \\
\hline 1. & $\begin{array}{l}\text { Minat belajar siswa } \\
\text { terhadap mata pelajaran } \\
\text { fisika menggunakan media } \\
\text { pembelajaran zooming } \\
\text { presentation }\end{array}$ & $70 \%$ & Baik \\
\hline 2. & $\begin{array}{l}\text { Penjelasan konsep suhu dan } \\
\text { kalor pada media } \\
\text { pembelajaran zooming } \\
\text { presentation }\end{array}$ & $76 \%$ & Baik \\
\hline 3. & $\begin{array}{l}\text { Pemanfaatan zoom in dan } \\
\text { zoom outpada media } \\
\text { pembelajaran zooming } \\
\text { presentation }\end{array}$ & $76 \%$ & Baik \\
\hline 4. & $\begin{array}{l}\text { Tampilan media } \\
\text { pembelajaran zooming } \\
\text { presentation }\end{array}$ & $82 \%$ & $\begin{array}{c}\text { Baik } \\
\text { Sekali }\end{array}$ \\
\hline \multicolumn{2}{|c|}{ Rata-rata } & $76 \%$ & Baik \\
\hline
\end{tabular}

Tabel 6 dapat dilihat bahwa 70\% siswa merasakan minat belajar yang positif dengan menggunakan media pembelajaran zooming presentation. Kemudian $76 \%$ siswa memberikan respon positif pada penjelasan konsep suhu dan kalor menggunakan media pembelajaran zooming presentation.Sebesar $76 \%$ siswa merasakan manfaat zoom in dan zoom out pada media pembelajaran zooming presentation. Selanjutnya sebesar $82 \%$ siswa menyatakan bahwa tampilan media pembelajaran menarik. Hal ini menyimpulkan bahwa secara keseluruhan penggunaan media pembelajaran zooming presentation dalam pembelajaran fisika konsep suhu dan kalor memperoleh hasil yang baik. Artinya penerapan media pembelajaran zooming presentation dapat diterima oleh para siswa.

\section{PENUTUP}

\section{Simpulan}

Berdasarkan hasil pengujian hipotesis menggunakan uji $t$, diperoleh nilai $t_{\text {hitung }}$ sebesar 4,53 dimana lebih besar dari nilai $t_{\text {tabel }}$ sebesar 1,988. Nilai rat-rata hasil belajar siswa kelas $\mathrm{X}$ yang menggunakan media pembelajaran zooming presentation bernilai 77,57 lebih tinggi dibandingkan rata-rata hasil belajar siswa tanpa menggunakan media zooming presentation dimana nilai rata-ratanya 68 . Pada saat pretest kemampuan kelas eksperimen dalam mengingat $\left(\mathrm{C}_{1}\right) \quad 27 \%$ meningkat menjadi $69 \%$, memahami $\left(\mathrm{C}_{2}\right) \quad 38 \%$ meningkat menjadi $82 \%$. Menerapkan $\left(\mathrm{C}_{3}\right) \quad 26 \%$ meningkat menjadi $76 \%$, menganalisis $\left(\mathrm{C}_{4}\right) 19 \%$ menjadi $72 \%$. Pada kelas kontrol kemampuan mengingat $\left(\mathrm{C}_{1}\right) 51 \%$ meningkat menjadi $65 \%$, memahami $\left(\mathrm{C}_{2}\right) 27 \%$ menjadi $79 \%$, menerapkan $\left(\mathrm{C}_{3}\right)$ 29\% menjadi $64 \%$, dan menganalisis $\left(\mathrm{C}_{4}\right)$ $25 \%$ menjadi $67 \%$. Dari data tersebut terlihat peningkatan jenjang kognitif antara pretest dan posttest adalah kelas eksperimen yang menggunakan media zooming presentation.

\section{Saran}

Media pembelajaran zooming presentation akan lebih optimal pemanfaatannya untuk menyajikan konsep fisika yang banyak memerlukan visualisasi objek mikroskopis, misalkan sistem tata surya, teori kinetik gas, dan termodinamika. dan lebih efektif jika disajikan juga bahan evaluasi siswa dalam proses pembelajaran berupa quiz maker. Dan berdasarkan hasil uji validitas ahli, media pembelajaran zooming presentation ini berada pada kategori baik. Namun, untuk pengembangannya perlu dilakukan perbaikan seperti, perpaduan warna, dan menambahkan audio, kemudian path yang disusun lebih detail lagi.

\section{DAFTAR PUSTAKA}

Anderson LW, David RK. 2010. Kerangka Landasan untuk Pembelajaran, Pengajaran, dan Asesmen, terj. Agung Prihantoro. Yogyakarta: Pustaka Belajar,

Diamond S. 2010. Prezi for Dummies. Kanada: Wiley Publishing.

Mohammad AE. 2011. Aplikasi Web 2.0 Tools dalam Pengajaran dan Pembelajaran. Malaysia: Pusat Pembangunan Akademik

Munir. 2012. Multimedia Konsep dan Aplikasi Dalam Pendidika. Bandung: Alfabeta.

Pechency A. 2010. Zooming User Interface: in Presentation For Learning. International Journal Information Theories and Applications 17(4).

Rosadi H. 2013. Pengembangan Media Slide berbasis Program Aplikasi Prezi Pada Materi Sistem Peredaran Darah Manusia Untuk Sekolah Menengah Pertama. Surabaya: Universitas Negeri Surabaya

Sudjana N. 2011. Penilaian Hasil Proses Belajar Mengajar. Bandung: Remaja Rosdakarya cet. 16. 
Sadiman AS, Raharjo R, Haryono A, Rahardjito. 1986. Media Pendidikan: Pengertian, Pengembagan, dan Pemanfaatannya. Jakarta: Raja Grafindo Persada.
Sugiyono. 2013. Metode Penelitian Pendidikan: Pendekatan Kuantitatif, Kualitatif, dan R\&D. Bandung: ALFABETA, cet. 18. 